\title{
Drug Treatments for Core Symptoms of Autism Spectrum Disorder: Unmet Needs and Future Directions
}

\author{
Luigi Mazzone Giulia Giovagnoli $^{3} \quad$ Martina Siracusano $^{1} \quad$ Valentina Postorino $^{4,5}$ Paolo Curatolo ${ }^{1}$ \\ ${ }^{1}$ Department of Neurosciences, Child Neurology and Psychiatry Unit, \\ Tor Vergata University Hospital of Rome, Rome, Italy \\ 2 Department of Neuroscience, I.R.C.C.S. Children's Hospital Bambino \\ Gesù, Rome, Italy \\ 3 Scientific Psychiatric Center Aita, Rome, Italy \\ ${ }^{4}$ Department of Pediatrics, Emory University School of Medicine, \\ Atlanta, Georgia, United States \\ ${ }^{5}$ Marcus Autism Center, Atlanta, Georgia, United States \\ J Pediatr Neurol 2017;15:134-142. \\ Address for correspondence Luigi Mazzone, MD, Department of \\ Neurosciences, Child Neurology and Psychiatry Unit, Tor Vergata \\ University Hospital of Rome, 00165 Rome, Italy \\ (e-mail: gigimazzone@yahoo.it).
}
Abstract
Keywords
- pharmacological treatments
- autism spectrum disorder
- genetic pathways
- mTOR
- bumetanide
- memantine
- arbaclofen
- oxytocin
- folinic acid

Pharmacological treatments for core symptoms of Autism Spectrum Disorder (ASD) are still lacking. The clinical heterogeneity observed in this population (e.g., differences in cognitive functioning or in autism symptom severity) should be taken into account when a new drug is tested. Stratifying this population according to its neurobiological substrate could significantly improve our knowledge regarding the most appropriate pharmacological treatment for individual needs. In this review, we discuss the possible genetic and biological pathways, including the Glutamatergic, GABAergic, and mTOR systems, involved in the pathophysiology of autism, as well as the mechanisms that may be targeted by new drug interventions. Finally, we describe the current progress from the preclinical and clinical studies on some potential therapeutic options for ASD core symptoms.

\section{Introduction}

Autism Spectrum Disorder (ASD) is a neurodevelopmental disorder characterized by impairment in social-communication skills, and restricted and repetitive interests in which manifestations of behavioral symptomology vary widely in severity. ${ }^{1}$ This condition has been diagnosed in an increasing number of children over the past 20 years, with the current prevalence estimates nearing $1 \%$ of the children. ${ }^{2}$ Due to the recent increase in prevalence rates of ASD, there is a strong need for efficient and cost-effective treatments for this population. $^{2,3}$ In 2013, during the Child and Adolescent Neuropsychopharmacology Network of the European
College of Neuropsychopharmacology (ECNP) in Barcelona, 13 experts held the Targeted Network Meeting (TNM) and identified the list of the largest unmet needs. ${ }^{4}$ To date, interventions commonly used for children and adolescents with ASD include behavioral therapy and medications. Despite considerable progress in understanding the neurobiology of ASD, established treatments for core symptoms are still needed. Drug interventions are focused on comorbid symptoms for the majority of psychiatric disorders with childhood or adolescence onset. ${ }^{5-7}$ However, all the medications prescribed to manage the comorbid symptoms (e.g., anxiety, depression) for this population are used "off label." 8,9 received

February 20, 2017 accepted after revision March 15, 2017 published online May 5, 2017
Issue Theme Advances in Autism Spectrum Disorder; Guest Editor: Paolo Curatolo, MD
DOI https://doi.org/

Copyright ( 2017 by Georg Thieme Verlag KG, Stuttgart · New York 10.1055/s-0037-1602823. ISSN 1304-2580. 
Ideally, the development of evidence-based treatment protocols combining pharmacological and behavioral interventions might help to improve outcomes and facilitate greater independence for individuals with ASD. ${ }^{10}$

Risperidone and aripiprazole have been approved by the U.S. Food and Drug Administration (FDA) for treating children with ASD accompanied by disruptive behavior (e.g., tantrums, aggression). ${ }^{11-14}$ Atypical antipsychotics mainly affect the activity of the classic neurotransmitter systems through binding to presynaptic or postsynaptic receptor systems. They are more potent as serotonin 2A (5-HT2A) than dopamine (DA) D2 antagonists; also, they are direct- or indirect-acting 5-HT1A receptor partial agonists. ${ }^{15}$ Despite the efficacy of these medications for treating behavioral problems, these medications do not improve the core symptoms of autism, suggesting that the main neurotransmitter systems do not directly affect the central pathophysiological pathways of this condition. ${ }^{4}$

By far, the main reason for the lack of effective drug interventions for the core symptoms of ASD is the limited understanding of its molecular and neurobiological bases. ${ }^{16}$ Moreover, the wide variety of genetic variants present in ASD that converge in different molecular pathways mediating the phenotypic expression in some identifiable core symptoms, make the development of new drug intervention challenging in this population. Translating the knowledge of molecular and neurobiological bases into individualized molecular therapies undoubtedly represents the most important long-term goal of genetic researches in autism. ${ }^{17}$

This article illustrates the possible genetic and neurobiological mechanisms involved in the pathophysiology of autism, and describes ways in which these mechanisms might be used for the development of new drug interventions by targeting the core symptoms of ASD. In addition, we provide an overview of the major challenges for the development of new effective drugs in this population. Finally, the unmet needs and future directions on drug treatments for core symptoms of ASD will be discussed.

\section{Genetic and Biological Pathways Involved in ASD: A Starting Point for New Treatments}

The understanding of the relationships between genetic variations and behavioral phenotypes is in its beginning. High number of genetic variants have been identified either as causal or contributing to autism, suggesting a substantial genetic heterogeneity of the disorder. However, the identification of specific biological pathways involved in ASD is particularly important since they could represent a starting point for the development of new drug interventions. ${ }^{18}$ In fact, there are significantly more chances of finding new, effective molecules affecting a limited number of abnormal biological pathways than developing a unique pharmacological agent for every single gene involved in the etiology of autism that has been identified so far.

Recent years have seen a rapid increase in the investigation of the pathophysiological pathways in ASD. ${ }^{19}$ Genetic and biological pathways play a role in drug sensitivity or resistance. Therefore, an essential step to robustly identify new drug interventions is to improve the knowledge on the pathways contributing to ASD. ${ }^{9}$

An example of a relevant biological pathway in ASD is the SH3 and multiple ankyrin repeat domains 3 (Shank3) pathway. ${ }^{20}$ Shank3 is a postsynaptic scaffold protein regulating synaptic development, function, and plasticity by coordinating the assembly of postsynaptic density (PSD) macromolecular signaling complex. ${ }^{21}$ It has been demonstrated that in mice germline, deletion of SHANK3 leads to autistic-like behaviors, including anxiety, social interaction deficits, and repetitive behaviors, by disrupting the protein composition of the PSD and reducing the neurotransmission efficiency. ${ }^{22}$ In the adult mice brain, restoration of Shank3 expression can promote spine formation; efficiently recruit major scaffolding and signaling proteins to the synapse; and assemble the PSD protein network even after the developmental period. ${ }^{21}$ Also, restoration of Shank3 expression highlights a correspondence between the biological substrate and the behavioral phenotype. Finally, in restoring Shank3 expression, mice have reported a significantly reduced grooming time and an enhanced social interaction compared with the wild type mice. ${ }^{21}$

Other recent studies have shown that ASD may be associated with an alteration of the excitatory/inhibitory (E/I) balance with abnormalities in the glutamate and GABA system, including neurotransmitters, receptors, and enzymes. ${ }^{23}$ The E/I imbalance refers to both the increased and the decreased E/I ratios, and is affected by factors controlling the formation and functioning of excitatory and inhibitory synapses in the brain. ${ }^{24}$ The $\mathrm{E} / \mathrm{I}$ ratio is highly asymmetric across development; it depends on the levels of ionotropic and metabotropic glutamate and GABA receptors, and on the extracellular glutamate and GABA concentrations. ${ }^{25}$ Indeed, recent studies have shown that the same gene mutation leads to distinct synaptic E/I imbalances in different synapses and brain regions at different time points. ${ }^{25}$ Specific factors that have a role in the synaptic E/I balance can include E/I synapse development and transmission; downstream signaling pathways; and homeostatic synaptic plasticity. ${ }^{26}$ At another level, $\mathrm{E} / \mathrm{I}$ balance has a role in the local circuits such as the interplay between GABAergic interneurons and target pyramidal neurons, which would modulate brain network and connections. Furthermore, results of postmortem studies showed a modification in GABAergic circuits in ASD with an alteration in the GABA-A and GABA-B receptors in postmortem brains of autistic individuals. ${ }^{27}$ At the clinical level, the E/I imbalance could explain the high occurrence of epilepsy in individuals with ASD. In fact, it may be the result of widespread changes in the GABA innervation and/or release, which may lower the threshold for developing seizures. ${ }^{28}$ Several researches exploring the comorbidity between ASD and epilepsy suggest heterogeneous changes in the glutamatergic and GABAergic systems in the brain of autism individuals and an overall increased ratio of E/I, which might lead to epileptic symptoms and atypical behaviors. ${ }^{29}$

In this context, the excitation and inhibition imbalances may have a role in the development and maintenance of autistic symptoms, and could be considered important 
therapeutic targets for future studies using animal models of ASD.

\section{Treatment of Core Symptoms: The Contribution of Syndromic Forms of ASD}

To date, strategies to improve drug development that aim at regulating the pathophysiological anomalies of a complex disorder have primarily been established through the study of single-gene disorders frequently associated with it. ${ }^{30}$ This could be a promising approach because these single-gene disorders might be treated by developing specific pharmacological compounds based on cellular, molecular, and animal models of well-known genetic syndromes. Subsequently, the same compounds might target different syndromes with similar pathological mechanisms. ${ }^{30}$ Promising results in humans have already been communicated for some of these drugs initially aimed at treating the original single-gene disorders. ${ }^{31}$

In this context, understanding the neurobiological alteration that a specific drug might target, is based on the study of new medications acting on known syndromic forms associated with autism, such as Joubert syndrome, Smith-LemliOpitz syndrome, tuberous sclerosis, or fragile X syndrome. ${ }^{32}$ In fact, abnormal biological pathways and causative genetic factors have been identified in these syndromic forms of autism. ${ }^{17}$ Different genes independently associated with autism, such as the tuberous sclerosis complex (TSC, i.e., TSC1 and TSC2), ${ }^{33}$ the phosphatase and tensin homolog (PTEN), ${ }^{34}$ and the neurofibromatosis type 1 (NF1), ${ }^{35}$ are all biologically and strictly related to the mammalian target of rapamycin (mTOR) pathway. ${ }^{36}$ In more detail, signaling through the metabotropic glutamate receptor 5 (mGluR5) as linked to the mTOR pathway has been implicated in the development of ASD in fragile X syndrome and TSC. ${ }^{37,38}$ The mTOR signaling pathway plays a role in regulating numerous cellular processes in the developing brain, including neuronal cell morphology, GABAergic interneurons development, and white matter connectivity. ${ }^{39}$ Therefore, the final common pathway in the development of an autistic brain might be a neuronal connectivity perturbation, in which abnormalities of local network information processing can interfere with the development of appropriate longrange connections among affected brain regions. ${ }^{40}$ Altered interneuron development, including a disruption in GABAergic interneurons, may account for an abnormal balance of $\mathrm{E} / \mathrm{I}$ ratio that can explain the concomitant presence of epilepsy and ASD in infants with TSC.

The mTOR pathways have recently been considered for the development of new effective drugs with novel mechanisms-by interacting with abnormal intracellular pathways and targeting core symptoms of ASD ${ }^{17,41}$ (see section "Treatment Targets On mTOR System").

Among the syndromic forms, fragile $\mathrm{X}$ syndrome is the most common genetic cause of autism, with a co-occurrence rate ranging from 2 to $6 \%{ }^{42}$ Fragile $\mathrm{X}$ syndrome is a genetic syndrome caused by the significant expansion of CGG triplet repeat within the fragile $X$ mental retardation 1 (FMR1) gene on the $\mathrm{X}$ chromosome. ${ }^{43}$ The FMR1 gene provides instruc- tions for making a protein called fragile $\mathrm{X}$ mental retardation protein (FMRP) that is widely expressed in neurons and glial cells, and acts as an "interactor" regulating the mRNA stability, translational control, and the synaptic plasticity in several encephalic regions. ${ }^{44}$ Indeed, its binding targets include the glutamate receptor 1 (GluR1) and the glutamate receptor 2 (GluR2) subunits of the amino-3-hydroxy-5methyl-4-isoxazole propionic acid (AMPA) glutamate receptor, and several other synaptic proteins important for neurotransmission and structure. ${ }^{45}$ Although the precise mechanism is less clear, deficiencies in FMRP are associated with increase in the mammalian target of rapamycin complex 1 (mTORC1) signaling. ${ }^{46}$

Animal models of fragile $\mathrm{X}$ syndrome (Fmr1-knockout [KO] mice) have been analyzed, and these animal studies have shown diverse abnormal features in mice, such as increased anxiety, locomotor activity, and cognitive deficits in different behavioral tasks. ${ }^{47}$ An analysis of synaptic plasticity in Fmr1-KO mice revealed that long-term depression (LTD) triggered by the metabotropic glutamate receptors (mGluRs) is enhanced, whereas the N-methyl-D-aspartate receptor (NMDA)-dependent LTD is normal. ${ }^{48}$ These results led to the proposal of "mGluR theory of fragile X Syndrome." This theory is based on the assumptions that many lasting consequences of group1 metabotropic glutamate receptor (Gp1 mGluR) activation require protein synthesis, and these are exaggerated in the absence of FMRP. Abnormal mGluR signaling could explain the peculiar clinical phenotypes of this syndrome. Therefore, an interesting line of research for future studies might focus on testing drug therapies that specifically target signaling by Gp1 mGluRs. This concept suggests a scientific rationale for the treatment of fragile $\mathrm{X}$ syndrome: if symptoms of fragile $\mathrm{X}$ syndrome arise from excessive signaling through Gp1 mGluRs, in principle, then it should be possible to treat them with drugs that inhibit the receptors and/or the downstream intracellular signals they initiate.

\section{Research on Pharmacological Treatment in ASD}

Different classes of pharmacological agents acting on different targets have been found to be effective in improving core symptoms of ASD. ${ }^{49}$ Studies in animal models on medications aimed at normalizing the $\mathrm{E} / \mathrm{I}$ imbalance through the use of mGluR antagonists ${ }^{50}$ and GABA agonists have shown promising results. ${ }^{51}$ Following the animal studies, clinical trials have been performed to test the potential role of glutamatergic and GABAergic agents in reversing the core social dysfunction in ASD. ${ }^{52,53}$

\section{Treatments Targeting the Glutamatergic Systems}

Among glutamatergic drugs, different therapeutic strategies have been developed to improve the core symptoms of autism that target metabotropic glutamate receptors (e.g., mGlu5 antagonists), AMPA receptors (e.g., the AMPA receptor potentiating drugs, ampakines), or NMDA receptors (e.g., the NMDA receptor antagonist, memantine). ${ }^{54}$ 
The mGlu5 antagonists that showed some effects on social and stereotypic behaviors in preclinical models of autism ${ }^{50}$ were then tested in patients with ASD and fragile X syndrome, and have shown promising results in a subgroup of these patients. ${ }^{31}$

In an autism mouse model (the BTBR mice), the 2-methyl6-(phenylethynyl)-pyridine (MPEP), an antagonist of the mGluR5 receptor, reduced repetitive self-grooming, whereas GRN-259, a selective negative allosteric modulator of the mGluR5 receptor, reduced repetitive behaviors in three cohorts of BTBR mice. Both compounds exhibited an increased improvement in the behavioral conditions and communication skills in these cohorts. ${ }^{52}$

Also, the experimental animal model on BTBR mice has been tested with ampakine compounds (CX1837 and CX1739, active on AMPA receptors). These succeeded in recovering the social impairment; however, these compounds exhibited inconsistent findings on repetitive self-grooming. ${ }^{52}$

Memantine, an affinity, partial antagonist of N-methyl-Daspartic acid (NMDA) glutamate receptor has also been tested in ASD clinical trials with contrasting results. ${ }^{55} \mathrm{~A}$ randomized, double-blind, placebo-controlled trial in 40 children with ASD treated with memantine reported a significant improvement of irritability, stereotypic behavior, and hyperactivity. ${ }^{56}$ In line with these results, Nikvarz et al, comparing the efficacy and side-effects of memantine versus risperidone for the treatment of ASD symptoms, suggested that memantine may have beneficial effects in improving several autism core symptoms. ${ }^{57}$ On the other hand, a recent randomized, placebo-controlled study in 121 children with ASD showed no clinical efficacy of memantine in this population. ${ }^{58}$

\section{Treatment Target on GABAergic Systems}

Animal models of Engrailed2 (En2) knockout mice have been proposed as a model for ASD, and a link between the altered function of En2, deficits of GABAergic systems, and the pathogenesis of ASD have also been postulated. ${ }^{59-61}$

In clinical trials, arbaclofen, a GABA-B receptor agonist that acts upstream of mGluR5 receptor signaling, has been investigated in fragile $\mathrm{X}$ syndrome, reporting promising findings in social domains. ${ }^{62}$ A recent open-label trial with STX209, a form of arbaclofen, was conducted in patients with ASD and displayed improvements in several outcome measures, including the Aberrant Behavior Checklist (ABC) Social Responsiveness, Social Withdrawal, and Lethargy subscale scores. ${ }^{63}$

\section{Treatment Target on mTOR System}

The dysregulation of intracellular signaling through the activation of mTOR pathway could play a direct role in determining the susceptibility to autism, and it is involved in the maintenance of the physiological synaptic E/I ratio. $^{39,40}$ Furthermore, a deregulation of mTOR signaling pathway has been linked to a wide variety of neurodevelopmental disorders including TSC. ${ }^{64}$ In this context, it can be hypothesized that mTOR inhibitors, a class of drugs selectively inhibiting mTOR complex and including rapamycin and everolimus, might also have a beneficial effect on
ASD symptoms. ${ }^{65}$ Everolimus has an established role in determining the shrinkage of TSC related lesions, such as subependymal giant cell astrocytomas ${ }^{66}$ and renal angiomyolipomas. ${ }^{67}$ More recently, its efficacy has been proved in reducing the seizure frequency in patients with TSC-related resistant focal seizures. ${ }^{68}$

Preclinical studies have also demonstrated that the administration of rapamycin, a selective inhibitor of mTOR complex to a mouse model of an early-onset epilepsy co-occurring with autism was not only able to reduce seizure susceptibility but could also attenuate autistic-like behaviors. ${ }^{39,69}$

Finally, there is also some preliminary clinical evidence of beneficial effects of mTOR inhibitors, including rapamycin and its analogue everolimus, on autistic symptoms in a few patients. ${ }^{65}$ Several clinical trials are already in progress to investigate the neurocognitive disorders and autism in TSC, as well as the possible efficacy and safety of mTOR inhibitors (Efficacy of RAD001/Everolimus in Autism and NeuroPsychological Deficits in Children With Tuberous Sclerosis Complex [RAPIT]-NCT01730209; Rapalogues for Autism Phenotype in TSC: A Feasibility Study [RAPT]-NCT01929642; and Trial of RAD001 and Neurocognition in Tuberous Sclerosis ComplexNCT01289912).

\section{Other Experimental Treatments}

\section{Oxytocin in ASD}

A large number of studies have also investigated the prominent role of oxytocin (OXT) as a potential treatment for the core symptoms of ASD with highly conflicting and heterogeneous findings. ${ }^{70,71}$

OXT receptors are localized in multiple regions of the brain, with especially high density in areas implicated in affective and social processing, thus supporting the role of this hormone in social behaviors. ${ }^{72}$ OXT is a neurosecretory hormone, synthesized by hypothalamic neurons that regulates the hypothalamic-pituitary-adrenal axis. ${ }^{73,74}$ In mammals, OXT is mainly involved in the regulation of reproduction, particularly in females, with peripheral OXT influencing parturition and lactation, and central OXT affecting mother- offspring bonding and recognition. ${ }^{73}$ More recently, OXT was also shown to stimulate trust and prosocial behaviors in typically developing individuals. Therefore, it is currently being evaluated for the treatment of autism symptoms. ${ }^{70,71,75}$ In support of an OXT contribution in ASD, studies have shown that children with autism have lower plasma OXT levels compared with the controls. ${ }^{76}$ Additionally, pharmacologic or genetic alterations in the OXT system have been associated with changes in the functional Magnetic Resonance Imaging (fMRI) of brain regions implicated in autism, including medial prefrontal cortex, hypothalamus, and amygdala. Genes coding for OXT (i.e., the OXT receptor, and the CD38) were found to be altered in certain cases of autism. ${ }^{77,78}$ Notably, preliminary data suggest that OXT treatment in individuals with autism can improve social skills. ${ }^{79-81}$ A double-blind, randomized, placebo-controlled, crossover clinical trial investigated the efficacy of OXT treatment in 31 children with autism and demonstrated that 
children receiving OXT showed significantly more improvements in social responsiveness compared with the children receiving placebo. ${ }^{71}$ However, despite a growing literature on OXT as a potential treatment for the core symptoms of autism, the mechanisms underlying OXT influence on complex social processes still remain largely unknown. ${ }^{71}$

\section{Bumetanide in ASD}

Recently, bumetanide, a medication approved by the FDA for treating edema related to congestive heart failure or kidney diseases, has been proposed as a promising treatment for the core symptoms of ASD. ${ }^{82}$ Studies on the offspring rodent models of autism have shown that maternal pretreatment with bumetanide may restore the control of electrophysiological and behavioral phenotypes. ${ }^{82-84}$ Following these encouraging animal studies, a randomized controlled study (RCT) demonstrated the effect of bumetanide in reducing autistic symptoms, compared with placebo in 60 children with autism or Asperger syndrome. Moderate side-effects restricted to an occasional mild hypokalemia were reported. $^{85}$ These results have been supported by a recent pilot study investigating the effects of combined bumetanide and applied behavior analysis (ABA) treatment compared with ABA treatment alone, in 60 children with autism. This study showed that the combined treatment (bumetanide + ABA treatment) may result in a better outcome in children with autism than ABA therapy alone. ${ }^{82}$ Therefore, bumetanide can be a promising novel therapeutic treatment for autism symptoms; however, larger trials are warranted.

\section{Folinic Acid in ASD}

Recent studies have identified several abnormalities in the metabolism of folate, showing that supplementation with folate during the prenatal and conception period might lower the risk of ASD in offspring. ${ }^{86}$ Low levels of cerebrospinal fluid (CSF) folate concentrations have been observed in up to $23 \%$ of children with ASD. ${ }^{87}$ Several case reports showed that a high dose of folinic acid markedly improves the symptoms in children with ASD and low CSF folate concentrations. Recently, a randomized, double-blind, placebo-controlled trial demonstrated that 48 children with ASD, who were treated with high dose of folinic acid improved in verbal communication as compared with the children treated with placebo. ${ }^{88}$

\section{Conclusion and Future Directions}

Despite remarkable advances in the knowledge of autism made in the past decade, the treatment of core symptoms remains a major challenge in ASD. The investigation of novel medications requires a robust preclinical phase with a validated animal model that displays a clinical phenotype similar to the core symptoms exhibited by the clinical population studied. Translating the knowledge from animal models to the clinic represents the most important long-term goal of research in the autism field. Defining the neural networks underlying ASD is crucial to identify the developmental correlates and cause of the disease, and establish the correct brain circuits for definite medications. Furthermore, studying the alteration of the neural networks consequent to a specific drug treatment might help to identify definite biological markers. Recent advances in the neuroimaging methodologies could undoubtedly help to address some of the challenges concerning the dynamic investigation of these neural substrates.

From a clinical stand point, to develop new medications targeting core symptoms, a critical point for the ASD research community is the need to develop a better definition of which symptoms are present in each individual affected by an ASD. By diagnosing comorbid disorders and defining ASD more clearly, we will be able to distinguish with greater accuracy the symptoms of comorbidities from the core symptoms of this condition. Until symptoms of ASD and comorbid disorders will not be defined more precisely, researchers will have difficulties in delineating clearly the outcome of pharmacologic interventions. It is possible that the phenotypic heterogeneity of autism may be reduced when more homogeneous subgroups based on shared biological etiology are considered. In this context, the stratification of patients according to their neurobiological substrate could significantly improve our knowledge about which specific pharmacological treatment is more appropriate for each individual's need. Furthermore, by identifying ASD subtypes, researchers might then be able to design new medications targeting specific autism symptoms. It is also crucial to take into account the different developmental stages when various treatments are used. For example, the measurement of E/I imbalance is influenced by subtypes of ASD (e.g., Fragile X, TSC, high-functioning, or low functioning) but also by the developmental period (e.g., GABA exerts a depolarizing and excitatory action early in postnatal life). It is possible that different intervention strategies need to be created according to the developmental phase of the brain.

Future studies should also use samples that are epidemiologically ascertained within both cross-sectional and longitudinal frameworks. Longitudinal clinical trials that begin as early as a diagnosis can be established; these could be very helpful in clarifying the relationships between developmental abnormalities and functional deficits in autistic children, and should be a priority for future research.

\section{References}

1 American Psychiatric Association. Report of DSM-5 Proposed Criteria for Autism Spectrum Disorder. American Psychiatric Association 2013

2 Developmental Disabilities Monitoring Network Surveillance Year 2010 Principal Investigators; Centers for Disease Control and Prevention (CDC). Prevalence of autism spectrum disorder among children aged 8 years - autism and developmental disabilities monitoring network, 11 sites, United States, 2010. MMWR Surveill Summ 2014;63:1-21

3 Wing L, Potter D. The epidemiology of autistic spectrum disorders: is the prevalence rising? Ment Retard Dev Disabil Res Rev 2002;8(03):151-161

4 Persico AM, Arango C, Buitelaar JK, et al; European Child and Adolescent Clinical Psychopharmacology Network. Unmet needs in paediatric psychopharmacology: present scenario and future perspectives. Eur Neuropsychopharmacol 2015;25(10):1513-1531 
5 Simonoff E, Pickles A, Charman T, Chandler S, Loucas T, Baird G. Psychiatric disorders in children with autism spectrum disorders: prevalence, comorbidity, and associated factors in a populationderived sample. J Am Acad Child Adolesc Psychiatry 2008;47(08): 921-929

6 Benvenuto A, Battan B, Porfirio MC, Curatolo P. Pharmacotherapy of autism spectrum disorders. Brain Dev 2013;35(02):119-127

7 Jobski K, Höfer J, Hoffmann F, Bachmann C. Use of psychotropic drugs in patients with autism spectrum disorders: a systematic review. Acta Psychiatr Scand 2017;135(01):8-28

8 Mazzone L, Ruta L, Reale L. Psychiatric comorbidities in asperger syndrome and high functioning autism: diagnostic challenges. Ann Gen Psychiatry 2012;11(01):16. Doi: 10.1186/1744-859X-11-16

9 Masi A, De Mayo MM, Glozier N, Guastella AJ. An overview of autism spectrum disorder, heterogeneity and treatment options. Neurosci Bull 2017. Doi: 10.1007/s12264-017-0100-y

10 Scahill L, Aman MG, McDougle CJ, et al. Trial design challenges when combining medication and parent training in children with pervasive developmental disorders. J Autism Dev Disord 2009; 39(05):720-729

11 McDougle CJ, Scahill L, McCracken JT, et al. Research units on pediatric psychopharmacology (RUPP) autism network. Background and rationale for an initial controlled study of risperidone. Child Adolesc Psychiatr Clin N Am 2000;9(01):201-224

12 Dove D, Warren Z, McPheeters ML, Taylor JL, Sathe NA, VeenstraVanderWeele J. Medications for adolescents and young adults with autism spectrum disorders: a systematic review. Pediatrics 2012;130(04):717-726

13 Food and Drug Administration (FDA). FDA approves the first drug to treat irritability associated with autism, risperdal. 2006. Available at: http://www.fda.gov/NewsEvents/Newsroom/PressAnnouncements/2006/ucm108759.htm. Accessed February 26, 2016

14 Bristol-Myers Squibb. U.S. ood and drug administration approves ABILIFY ${ }^{\circledR}$ (aripiprazole) for the treatment of irritability associated with autistic disorder in pediatric patients (Ages 6 to 17 Years). Available at: http://news.bms.com/press-release/ rd-news/us-food-and-drug-administration-approves-abilify-aripiprazole-treatment-irrita. Accessed April 19, 2016

15 Kuroki T, Nagao N, Nakahara T. Neuropharmacology of secondgeneration antipsychotic drugs: a validity of the serotonin-dopamine hypothesis. Prog Brain Res 2008;172:199-212

16 Gandal MJ, Leppa V, Won H, Parikshak NN, Geschwind DH. The road to precision psychiatry: translating genetics into disease mechanisms. Nat Neurosci 2016;19(11):1397-1407

17 Vorstman JA, Ophoff RA. Genetic causes of developmental disorders. Curr Opin Neurol 2013;26(02):128-136

18 Chahrour M, O'Roak BJ, Santini E, Samaco RC, Kleiman RJ, Manzini MC. Current perspectives in autism spectrum disorder: from genes to therapy. J Neurosci 2016;36(45):11402-11410

19 Monteiro P, Feng G. SHANK proteins: roles at the synapse and in autism spectrum disorder. Nat Rev Neurosci 2017;18(03): 147-157

20 Durand CM, Perroy J, Loll F, et al. SHANK3 mutations identified in autism lead to modification of dendritic spine morphology via an actin-dependent mechanism. Mol Psychiatry 2012;17(01):71-84

21 Mei Y, Monteiro P, Zhou Y, et al. Adult restoration of Shank3 expression rescues selective autistic-like phenotypes. Nature 2016;530(7591):481-484

22 Yang M, Bozdagi O, Scattoni ML, et al. Reduced excitatory neurotransmission and mild autism-relevant phenotypes in adolescent Shank3 null mutant mice. J Neurosci 2012;32(19):6525-6541

23 Pizzarelli R, Cherubini E. Alterations of GABAergic signaling in autism spectrum disorders. Neural Plast 2011;2011:297153. Doi: $10.1155 / 2011 / 297153$

24 Uzunova G, Pallanti S, Hollander E. Excitatory/inhibitory imbalance in autism spectrum disorders: Implications for interventions and therapeutics. World J Biol Psychiatry 2016;17(03):174-186
25 Coghlan S, Horder J, Inkster B, Mendez MA, Murphy DG, Nutt DJ. GABA system dysfunction in autism and related disorders: from synapse to symptoms. Neurosci Biobehav Rev 2012;36(09): 2044-2055

26 Port RG, Gaetz W, Bloy L, et al. Exploring the relationship between cortical GABA concentrations, auditory gamma-band responses and development in ASD: Evidence for an altered maturational trajectory in ASD. Autism Res2016. Doi: 10.1002/aur.1686

27 Fatemi SH, Reutiman TJ, Folsom TD, Rustan OG, Rooney RJ, Thuras PD. Downregulation of GABAA receptor protein subunits $\alpha 6, \beta 2, \delta$, $\varepsilon, \gamma 2, \theta$, and $\rho 2$ in superior frontal cortex of subjects with autism. J Autism Dev Disord 2014;44(08):1833-1845

28 Brooks-Kayal A. Epilepsy and autism spectrum disorders: are there common developmental mechanisms? Brain Dev 2010; 32(09):731-738

29 Buckley AW, Holmes GL. Epilepsy and autism. Cold Spring Harb Perspect Med 2016;6(04):a022749. Doi: 10.1101/cshperspect. a022749

30 Persico M, Di Dato A, Orteca N, Cimino P, Novellino E, Fattorusso C. Use of integrated computational approaches in the search for new therapeutic agents. Mol Inform 2016;35(8-9):309-325

31 Jacquemont S, Berry-Kravis E, Hagerman R, et al. The challenges of clinical trials in fragile $\mathrm{X}$ syndrome. Psychopharmacology (Berl) 2014;231(06):1237-1250

32 Geschwind DH. Genetics of autism spectrum disorders. Trends Cogn Sci 2011;15(09):409-416

33 Curatolo P, Moavero R, de Vries PJ. Neurological and neuropsychiatric aspects of tuberous sclerosis complex. Lancet Neurol 2015;14(07):733-745

34 Zhou J, Parada LF. PTEN signaling in autism spectrum disorders. Curr Opin Neurobiol 2012;22(05):873-879

35 Walsh KS, Vélez JI, Kardel PG, et al. Symptomatology of autism spectrum disorder in a population with neurofibromatosis type 1 . Dev Med Child Neurol 2013;55(02):131-138

36 Ehninger D. From genes to cognition in tuberous sclerosis: implications for mTOR inhibitor-based treatment approaches. Neuropharmacology 2013;68:97-105

37 Auerbach BD, Osterweil EK, Bear MF. Mutations causing syndromic autism define an axis of synaptic pathophysiology. Nature 2011;480(7375):63-68

38 Wenger TL, Kao C, McDonald-McGinn DM, et al. The role of mGluR copy number variation in genetic and environmental forms of syndromic autism spectrum disorder. Sci Rep 2016;6:19372. Doi: 10.1038/srep19372

39 Ehninger D, Han S, Shilyansky C, et al. Reversal of learning deficits in a Tsc2 $+/$ - mouse model of tuberous sclerosis. Nat Med 2008; 14(08):843-848

40 Powell EM, Campbell DB, Stanwood GD, Davis C, Noebels JL, Levitt P. Genetic disruption of cortical interneuron development causes region- and GABA cell type-specific deficits, epilepsy, and behavioral dysfunction. J Neurosci 2003;23(02):622-631

41 Curatolo P, Napolioni V, Moavero R. Autism spectrum disorders in tuberous sclerosis: pathogenetic pathways and implications for treatment. J Child Neurol 2010;25(07):873-880

42 Lozano R, Azarang A, Wilaisakditipakorn T, Hagerman RJ. Fragile X syndrome: a review of clinical management. Intractable Rare Dis Res 2016;5(03):145-157

43 Bagni C, Oostra BA. Fragile X syndrome: from protein function to therapy. Am J Med Genet A 2013;161A(11):2809-2821

44 Bardoni B, Capovilla M, Lalli E. Modeling Fragile X syndrome in neurogenesis: an unexpected phenotype and a novel tool for future therapies. Neurogenesis (Austin) 2017;4(01):e1270384. Doi: $10.1080 / 23262133.2016 .1270384$

45 Guo W, Polich ED, Su J, et al. Fragile X Proteins FMRP and FXR2P control synaptic GluA1 expression and neuronal maturation via distinct mechanisms. Cell Reports 2015;11(10):1651-1666

46 Sato A. mTOR, a potential target to treat autism spectrum disorder. CNS Neurol Disord Drug Targets 2016;15(05):533-543 
47 Bernardet M, Crusio WE. Fmr1 KO mice as a possible model of autistic features. Sci World J 2006;6:1164-1176

48 Huber KM, Gallagher SM, Warren ST, Bear MF. Altered synaptic plasticity in a mouse model of fragile $\mathrm{X}$ mental retardation. Proc Natl Acad Sci U S A 2002;99(11):7746-7750

49 Canitano R. New experimental treatments for core social domain in autism spectrum disorders. Front Pediatr 2014;2:61. Doi: 10.3389/fped.2014.00061

50 Burket JA, Herndon AL, Winebarger EE, Jacome LF, Deutsch SI. Complex effects of mGluR5 antagonism on sociability and stereotypic behaviors in mice: possible implications for the pharmacotherapy of autism spectrum disorders. Brain Res Bull 2011; 86(3-4):152-158

51 Silverman JL, Pride MC, Hayes JE, et al. GABAB receptor agonist RBaclofen reverses social deficits and reduces repetitive behavior in two mouse models of autism. Neuropsychopharmacology 2015;40(09):2228-2239

52 Silverman JL, Oliver CF, Karras MN, Gastrell PT, Crawley JN. Ampakine enhancement of social interaction in the BTBR mouse model of autism. Neuropharmacology 2013;64:268-282

53 Veenstra-VanderWeele J, Cook EH, King BH, et al. Arbaclofen in children and adolescents with autism spectrum disorder: A randomized, controlled, phase 2 trial. Neuropsychopharmacology 2016. Doi: 10.1038/npp.2016.237

54 Hollander E, Uzunova G. Are there new advances in the pharmacotherapy of autism spectrum disorders? World Psychiatry 2017; 16(01):101-102

55 Hosenbocus S, Chahal R. Memantine: a review of possible uses in child and adolescent psychiatry. J Can Acad Child Adolesc Psychiatry 2013;22(02):166-171

56 Ghaleiha A, Asadabadi M, Mohammadi MR, et al. Memantine as adjunctive treatment to risperidone in children with autistic disorder: a randomized, double-blind, placebo-controlled trial. Int J Neuropsychopharmacol 2013;16(04):783-789

57 Nikvarz N, Alaghband-Rad J, Tehrani-Doost M, Alimadadi A, Ghaeli P. Comparing efficacy and side effects of memantine vs. risperidone in the treatment of autistic disorder. Pharmacopsychiatry 2017;50(01):19-25

58 Aman MG, Findling RL, Hardan AY, et al. Safety and efficacy of memantine in children with autism: randomized, placebo-controlled study and open-label extension. J Child Adolesc Psychopharmacol 2016. Doi: 10.1089/cap.2015.0146

59 Cheh MA, Millonig JH, Roselli LM, et al. En2 knockout mice display neurobehavioral and neurochemical alterations relevant to autism spectrum disorder. Brain Res 2006;1116(01):166-176

60 Benayed R, Choi J, Matteson PG, et al. Autism-associated haplotype affects the regulation of the homeobox gene, ENGRAILED 2. Biol Psychiatry 2009;66(10):911-917

61 Provenzano G, Clementi E, Genovesi S, et al. GH dysfunction in Engrailed-2 knockout mice, a model for autism spectrum disorders. Front Pediatr 2014;2:92. Doi: 10.3389/fped.2014.00092

62 Berry-Kravis EM, Hessl D, Rathmell B, et al. Effects of STX209 (arbaclofen) on neurobehavioral function in children and adults with fragile $\mathrm{X}$ syndrome: a randomized, controlled, phase 2 trial. Sci Transl Med 2012;4(152):152ra127. Doi: 10.1126/ scitranslmed.3004214

63 Erickson CA, Veenstra-Vanderweele JM, Melmed RD, et al. STX209 (arbaclofen) for autism spectrum disorders: an 8-week openlabel study. J Autism Dev Disord 2014;44(04):958-964

64 Napolioni V, Moavero R, Curatolo P. Recent advances in neurobiology of tuberous sclerosis complex. Brain Dev 2009;31(02): 104-113

65 Kilincaslan A, Kok BE, Tekturk P, Yalcinkaya C, Ozkara C, Yapici Z. Beneficial effects of everolimus on autism and attention-deficit/ hyperactivity disorder symptoms in a group of patients with tuberous sclerosis complex. J Child Adolesc Psychopharmacol 2016. Doi: $10.1089 /$ cap.2016.0100
66 Franz DN, Belousova E, Sparagana S, et al. Efficacy and safety of everolimus for subependymal giant cell astrocytomas associated with tuberous sclerosis complex (EXIST-1): a multicentre, randomised, placebo-controlled phase 3 trial. Lancet 2013; 381(9861):125-132

67 Bissler JJ, Kingswood JC, Radzikowska E, et al. Everolimus for angiomyolipoma associated with tuberous sclerosis complex or sporadic lymphangioleiomyomatosis (EXIST-2): a multicentre, randomised, double-blind, placebo-controlled trial. Lancet 2013;381(9869):817-824

68 French JA, Lawson JA, Yapici Z, et al. Adjunctive everolimus therapy for treatment-resistant focal-onset seizures associated with tuberous sclerosis (EXIST-3): a phase 3, randomised, double-blind placebo-controlled study. Lancet 2016;388(10056):2153-2163

69 Talos DM, Sun H, Zhou X, et al. The interaction between early life epilepsy and autistic-like behavioral consequences: a role for the mammalian target of rapamycin (mTOR) pathway. PLoS One 2012;7(05):e35885. Doi: 10.1371/journal.pone.0035885

70 Guastella AJ, Gray KM, Rinehart NJ, et al. The effects of a course of intranasal oxytocin on social behaviors in youth diagnosed with autism spectrum disorders: a randomized controlled trial. J Child Psychol Psychiatry 2015;56(04):444-452

71 Yatawara CJ, Einfeld SL, Hickie IB, Davenport TA, Guastella AJ. The effect of oxytocin nasal spray on social interaction deficits observed in young children with autism: a randomized clinical crossover trial. Mol Psychiatry 2016;21(09):1225-1231

72 Bethlehem RAI, Baron-Cohen S, van Honk J, Auyeung B, Bos PA. The oxytocin paradox. Front Behav Neurosci 2014;8:48. Doi: 10.3389/fnbeh.2014.00048

73 Ross HE, Young LJ. Oxytocin and the neural mechanisms regulating social cognition and affiliative behavior. Front Neuroendocrinol 2009;30(04):534-547

74 Bethlehem RA, van Honk J, Auyeung B, Baron-Cohen S. Oxytocin, brain physiology, and functional connectivity: a review of intranasal oxytocin fMRI studies. Psychoneuroendocrinology 2013; 38(07):962-974

75 Dadds MR, MacDonald E, Cauchi A, Williams K, Levy F, Brennan J. Nasal oxytocin for social deficits in childhood autism: a randomized controlled trial. J Autism Dev Disord 2014;44(03):521-531

76 Husarova VM, Lakatosova S, Pivovarciova A, et al. Plasma oxytocin in children with autism and its correlations with behavioral parameters in children and parents. Psychiatry Investig 2016; 13(02):174-183

77 Di Napoli A, Warrier V, Baron-Cohen S, Chakrabarti B. Genetic variation in the oxytocin receptor (OXTR) gene is associated with Asperger Syndrome. Mol Autism 2014;5(01):48. Doi: 10.1186/ 2040-2392-5-48

78 Watanabe $\mathrm{T}$, Otowa $\mathrm{T}$, Abe $\mathrm{O}$, et al. Oxytocin receptor gene variations predict neural and behavioral response to oxytocin in autism. Soc Cogn Affect Neurosci 2017;12(03):496-506

79 Guastella AJ, Einfeld SL, Gray KM, et al. Intranasal oxytocin improves emotion recognition for youth with autism spectrum disorders. Biol Psychiatry 2010;67(07):692-694

80 Anagnostou E, Soorya L, Chaplin W, et al. Intranasal oxytocin versus placebo in the treatment of adults with autism spectrum disorders: a randomized controlled trial. Mol Autism 2012;3(01): 16. Doi: $10.1186 / 2040-2392-3-16$

81 Domes G, Kumbier E, Heinrichs M, Herpertz SC. Oxytocin promotes facial emotion recognition and amygdala reactivity in adults with asperger syndrome. Neuropsychopharmacology 2014;39(03):698-706

82 Du L, Shan L, Wang B, et al. A pilot study on the combination of applied behavior analysis and bumetanide treatment for children with autism. J Child Adolesc Psychopharmacol 2015;25(07):585-588

83 Tyzio R, Nardou R, Ferrari DC, et al. Oxytocin-mediated GABA inhibition during delivery attenuates autism pathogenesis in rodent offspring. Science 2014;343(6171):675-679 
84 Lemonnier E, Ben-Ari Y. The diuretic bumetanide decreases autistic behaviour in five infants treated during 3 months with no side effects. Acta Paediatr 2010;99(12):1885-1888

85 Lemonnier E, Degrez C, Phelep M, et al. A randomised controlled trial of bumetanide in the treatment of autism in children. Transl Psychiatry 2012;2:e202. Doi: 10.1038/ tp.2012.124

86 Steenweg-de Graaff J, Ghassabian A, Jaddoe VW, Tiemeier H, Roza SJ. Folate concentrations during pregnancy and autistic traits in the offspring. The generation R study. Eur J Public Health 2015; 25(03):431-433

87 Shoffner J, Trommer B, Thurm A, et al. CSF concentrations of 5-methyltetrahydrofolate in a cohort of young children with autism. Neurology 2016;86(24):2258-2263

88 Frye RE, Slattery J, Delhey L, et al. Folinic acid improves verbal communication in children with autism and language impairment: a randomized double-blind placebo-controlled trial. Mol Psychiatry 2016;00:1-10 